\title{
Austeridade fiscal versus contabilidade criativa: uma nova práxis para o velho ímpeto oportunista*
}

Saulo Souza**

Resumo

Este trabalho se detém na habilidade dos governos estaduais em preservar os benefícios políticos tradicionais do gasto público num ambiente caracterizado pela adoção de regras de austeridade fiscal. O pressuposto é que, não obstante as reformas de estabilização fiscal no Brasil, mantêm-se abertas as janelas de oportunidade para o comportamento fiscal oportunista. A implicação é dúplice: indisciplina fiscal e criação de problemas intertemporais de déficit. 0 trabalho conclui, então, que o recurso à contabilidade criativa pode explicar situações em que o governante, de quem se espera terminar o mandato quite com as regras, deixa débitos para a gestão sucessora.

Palavras-chave: Regras fiscais, oportunismo fiscal, eleições, contabilidade criativa.

\section{Introdução: os termos do debate}

Um recente aspecto do federalismo fiscal brasileiro é a busca pelos governos subnacionais de mecanismos que garantam o cumprimento de metas fiscais estabelecidas pelo governo federal, todavia não ao custo do desempenho eleitoral. Este trabalho se detém na análise de como a adoção de regras de austerida de fiscal traz a reboque consequências antagônicas para os estados brasileiros, acarretando, por um lado, a garantia de uma inusitada austeridade nas contas públicas e revelando, por outro, uma habilidade dos governantes em preservar os benefícios políticos tradicionais do gasto público num ambiente hostil à dívida, ao déficit e ao endividamento.

Com as reformas de estabilização fiscal que entram em vigor no início da década de 2000, o federalismo brasileiro adota um modelo que deveras privilegia o Executivo federal, haja vista sua prerrogativa de definir metas de superávit primário e limitar o gasto público nos três níveis de governo. A uma, as reformas dificultam

\footnotetext{
* Sou grato a Marcus Melo e Carlos Pereira pela utilização de dados, anális e de regressão e construção da argumentação utilizada neste artigo.

** Doutor pela Universidade de Cambridge e pela Universidade Federal de Pernambuco, professor na Faculdade ASCES. Email: souzasaulo@hotmail.com.
} 
sobremaneira a emissão de títulos públicos, o que equivale a forçar os estados a declinar do recurso ao endividamento. Isso porque ao endividamento seguir-se-iam a inadimplência e a necessidade de socorro financeiro na modalidade de refinanciamento de passivos. A duas, o governo federal se dá a prerrogativa de reter ou reduzir o montante das transferências operadas por intermédio de convênios com os estados, instituindo, com isso, gravames aos entes deficitários.

Sob a ótica política, o propósito é impor custos aos estados que não investirem em políticas de interesse federal, como no caso dos repasses para o sistema de saúde. Ainda que o impacto dessas transferências seja amenizado com a ampliação das proveniências tributárias decorrentes do crescimento econômico no Brasil, a dificuldade legal de os governantes utilizarem essas receitas para fins eleitorais é agora patente. Assim a possibilidade de retenção dos repasses gera o efeito adverso de minorar o poder de barganha dos governadores, de maneira que a redução da mobilidade alocativa se dá também com o temor à perda de transferências intergovernamentais.

Outra consequência considerável é a redução dos efeitos dos ciclos políticos no orçamento. Senão vejamos. A introdução da Lei de Responsabilidade Fiscal (LC 101/2000) vem com o abate das despesas de final de mandato, até então utilizadas pelos governadores para atração de votos de última hora. Em outras palavras, a regra busca dificultar o chamado "voto de cabresto", fonte obtusa de apoio eleitoral. A anuência dos estados em não absorver no cofre o impulso cíclico do excesso de gastos deve-se em muito ao acordo político celebrado por ocasião da aprovação da regra, quando engenhosamente o governo federal garante voz às bancadas regionais no Congresso. Em troca de suporte para aprovação da Emenda de Reeleição, os estados concordam em aprovar a LRF sem grandes modificações em relação ao texto original.

Entretanto, pelo menos quatro elementos do status quo subsistem a esse processo: primeiro, as demandas sociais continuam a crescer não obstante a menor capacidade de dispêndio dos estados; segundo, as pressões do período eleitoral continuam a afetar a destinação do gasto público, sendo paradoxalmente majoradas com a possibilidade de reeleição dos governadores; terceiro, a imagem junto ao eleitorado de governo austero com as contas públicas não compensa eventuais 
necessidades de direcionamento de gastos a áreas de interesse dos governantes e de sua base de apoio partidário, e; quarto, a União falha ao não dotar os órgãos fiscalizadores subnacionais de independência política exigida à manutenção da austeridade fiscal em níveis razoáveis, o que mantém abertas as janelas de oportunidade para o comportamento fiscal oportunista. Em consequência, enquanto em um front os governos estaduais adotam medidas para o cumprimento das novas regras, em outro passam a buscar mecanismos que os habilitem a satisfazer seus interesses políticos e os de seus constituintes.

É em razão do acima discutido que a estrutura de incentivos presente no federalismo fiscal brasileiro na primeira década do século 21 replica um dilema próprio da administração do gasto público, quando os governadores buscam estratégias para ajustar as contas sem com isso comprometer em seu sucesso nas urnas. A saída para o dilema é encontrada na construção de uma práxis que se funda, como se verá adiante, na busca de mecanismos que garantam o cumprimento das metas fiscais, todavia não ao custo do seu desempenho eleitoral. Se a macro-composição do gasto apresenta pouca variação no período mais recente, face à rigidez que se imprime sobre as contas públicas, a micro-composição das despesas - e não sua magnitude - obedece a um padrão que favorece a mobilidade alocativa dos governos. Eis o argumento principal do trabalho.

O dilema adquire relevância na contemporaneidade quando se contempla a necessidade de se frearem tendências expansionistas do gasto público para além do que prescrevem as regras derivadas da reforma de estabilização fiscal, num tempo em que os governos buscam sanear problemas sociais crescentes e, por meio disso, garantir a governabilidade e o eventual sucesso nas urnas. Se, por um lado, constatar a ubiquidade do oportunismo fiscal não é qualquer novidade, é analiticamente válido, por outro, inquirir por que as regras fiscais subsistem a despeito de tangencialmente vexarem propósitos político-partidários, o que firma os mecanismos de escape como elementos centrais de análise. A identificação da natureza, manifestação e efeitos desses mecanismos importa, então, para a demarcação dos limites da disciplina fiscal dos governos. 
O restante do artigo é organizado como segue. A seção 2 aborda a influência das regras fiscais e as formas alternativas de mensuração da disciplina fiscal. A seção 3 trata do uso oportunista dos restos a pagar. A noção de contabilidade criativa é visitada na seção 4 . A seção 5 pondera a relevância de fatores legais e institucionais no resultado fiscal. A seção 6 busca associação estatística entre variáveis políticas e institucionais e o oportunismo fiscal, concluindo o trabalho com as suas considerações finais.

\section{Metas, equilíbrio e mobilidade alocativa}

Do ponto de vista das regras de austeridade fiscal no Brasil, os incentivos à manutenção do equilíbrio se apresentam ex ante, como sendo o conjunto de metas que disciplinam a rotina fiscal dos governos subnacionais. Por conseguinte, a magnitude dessas metas é que determina a natureza dos constraints infligidos aos estados. As metas também atuam como ferramenta anticíclica quando impedem medidas expansionistas motivadas pela época das eleições. De fato, parece não haver dúvidas de que as metas de superávit primário vão obter sensível êxito junto aos governos estaduais, se compararmos as médias de resultado atuais com as de então. O gráfico da Figura 1 adiante indica que a performance fiscal das unidades federadas é visivelmente superior após 2000. A se julgar pelo parâmetro do superávit primário apenas, a disciplina fiscal seria o lema dos estados, já que o resultado preserva-se positivo em todo o período, sem exclusão dos anos eleitorais. Todavia, no seu valor total está intrínseco o resultado obtido pelas estatais, o que facilita o alcance das metas quando as empresas geram lucros e contribuem para o melhoramento da Receita Corrente Líquida. Em grande medida, essa amplificação artificial da RCL compensa eventuais aumentos de gastos. Ademais, na metodologia de cálculo do indicador não se computam os valores pagos e recebidos a título de juros e amortizações da dívida. Sendo assim, é possível que governos deficitários (no conceito orçamentário básico de receitas menos despesas) apresentem resultado positivo. 
Figura 1 - Média do resultado primário dos estados em \% RCL

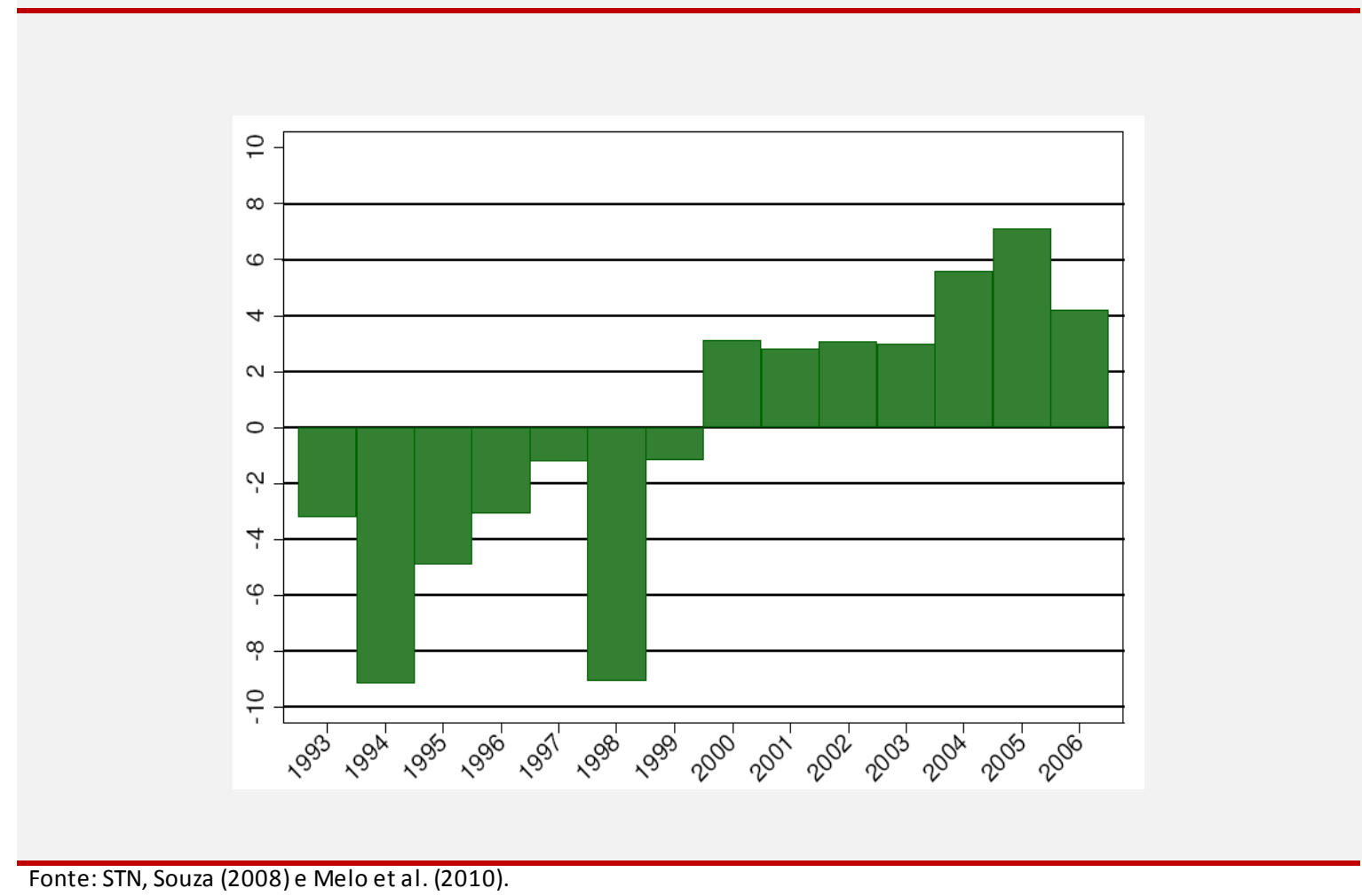

Fonte: STN, Souza (2008) e Melo et al. (2010).

Pode-se, então, concluir que o critério de geração de superávits fiscais é, por si só, insuficiente para se entender o comportamento dos entes federados. Outra forma comum de se avaliar o esforço fiscal é, em vez do resultado primário, o nominal, no qual os valores dos juros da dívida são acrescentados. O resultado nominal manifesta a Necessidade de Financiamento do Setor Público (NFSP), ou seja, o montante de recursos que o governo necessita captar junto ao sistema financeiro ou ao setor privado para resguardar suas despesas orçamentárias. Por este critério os algarismos do desempenho fiscal são assaz inferiores aos do resultado primário, tendo média negativa em quase todo o período de vigência da LRF e com queda nos anos eleitorais, o que entra em litígio com a evolução do resultado primário.

A discrepância entre os indicadores (déficit nominal e, simultaneamente, superávit primário) tem sido explicada em função das elevadas despesas com serviços da dívida. Carece de sentido, porém, alegar que o déficit nominal se justifica pelos valores reservados para pagamento das dívidas com a União, uma vez que eles são, em muitos casos, superados pela diferença entre os dois resultados, levando à 
consumação de também não ser o resultado nominal o melhor índice de disciplina fiscal. Logo, uma diferenciação deve ser feita entre as formas convencionais de mensuração da disciplina fiscal e uma alternativa, porém menos utilizada para este fim: a disponibilidade ou suficiência de caixa. A LRF exige a confrontação entre as obrigações financeiras dos governos com os recursos que detêm no fim do ano: a diferença negativa corresponde à insuficiência de caixa. Isto acontece, por exemplo, quando as despesas pendentes de pagamento ultrapassam as disponibilidades do tesouro ${ }^{1}$.

Para se enxergar a real situação das contas públicas ao final de cada exercício deve-se, portanto, olhar para além do resultado primário ou nominal e fitar com atenção os haveres de caixa. Para fins de elucidação, o gráfico da Figura 2 compara os indicadores.

\section{Figura 2 - Indicadores de disciplina fiscal}

\footnotetext{
${ }^{1}$ Para apurar a suficiência de caixa, Gobetti e Klering (2007) levam em conta, além dos restos a pagar, os depósitos judiciais e demais obrigações financeiras registradas nos relatórios de gestão fiscal.
} 
Há insuficiência de caixa em toda a série temporal, embora o resultado primário persista superavitário em todos os exercícios e haja resultado nominal positivo nalguns. Ademais, a insuficiência está diretamente relacionada ao percentual de despesas pendentes de pagamento, i.e inscritas em restos a pagar, conforme ilustra o gráfico presente na Figura 3.

Figura 3 - Restos a pagar (média dos estados)

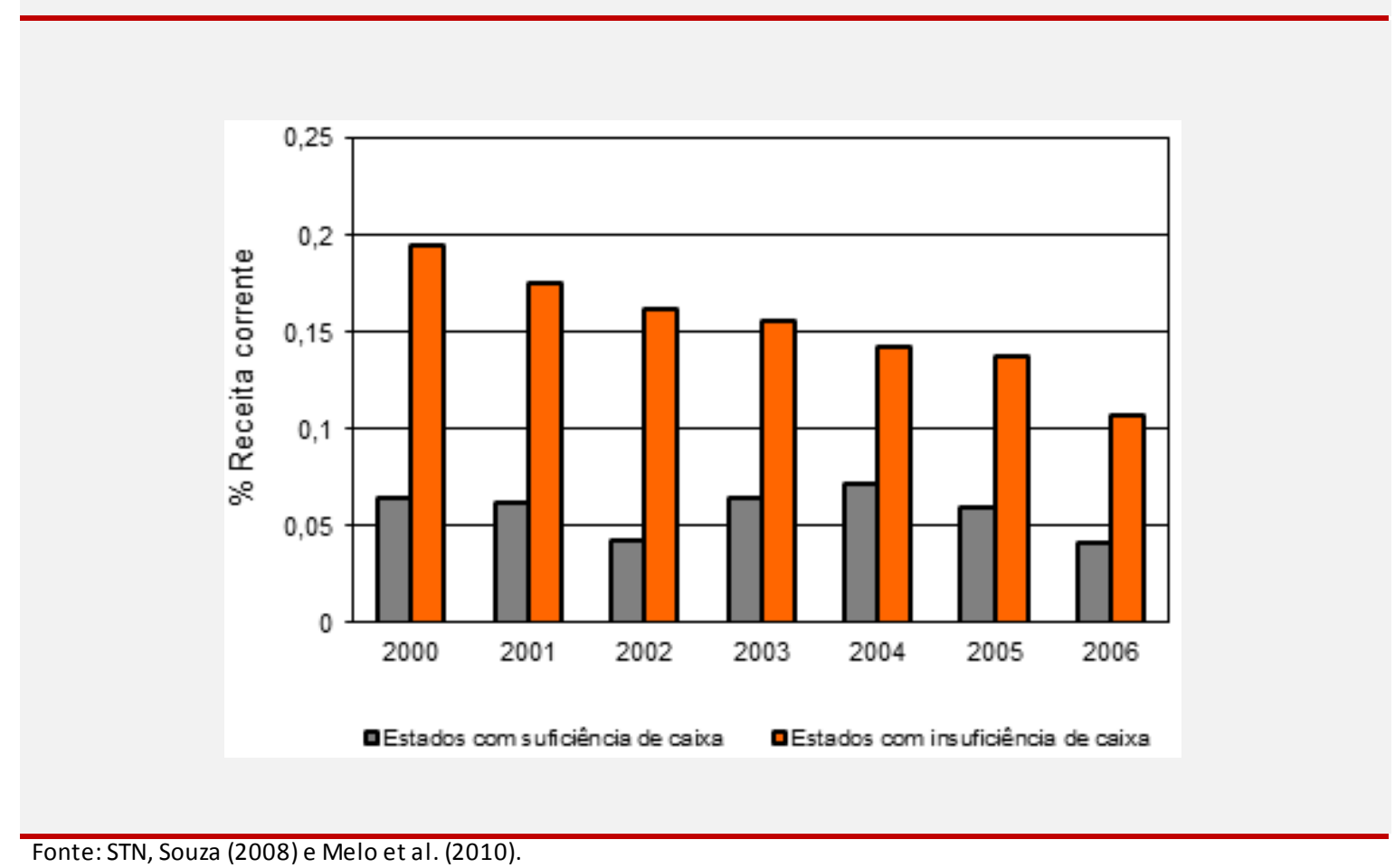

Fonte: STN, Souza (2008) e Melo et al. (2010).

Tem-se então que uma elevada proporção de despesas inscritas nos restos a pagar concorre para a ampliação do desequilíbrio fiscal no exercício ou, no mínimo, para a redução da capacidade de dispêndio no exercício seguinte. A implicação é, portanto, dúplice: indisciplina fiscal e criação de problemas intertemporais de déficit. Por que, então, os governos insistem em utilizar este mecanismo? Respostas a esta questão podem explicar situações em que o governador, de quem se espera terminar o mandato quite com as regras, deixa débitos para a gestão sucessora. 


\section{Restos a pagar: uma proxy do comportamento oportunista}

Deduz-se do discutido na subseção anterior que a mensuração da disciplina fiscal deve ter por base não somente o equilíbrio entre receitas e despesas nãofinanceiras, mas igualmente a forma como esses elementos são registrados na contabilidade pública. Sem embargo, o recurso dos restos a pagar facilita a mobilidade alocativa na medida em que o governante prioriza a realização e/ou o pagamento de despesas em detrimento de outras. Em razão disso, o excedente de despesas inscrito nos restos pode ser usado como proxy do comportamento fiscal oportunista.

A Figura 4 a seguir detalha os principais itens inscritos em restos a pagar, onde se vê que a mobilidade neste nível de manejo orçamentário é muito maior que nas despesas agregadas por função. Adicionalmente, os investimentos de capital (que inclui obras públicas) são comparados com as modalidades possíveis de restos a pagar $^{2}$.

Figura 4: Investimentos, restos a pagar e suficiência de caixa (\% despesa corrente)

Estados com suficiência de caixa

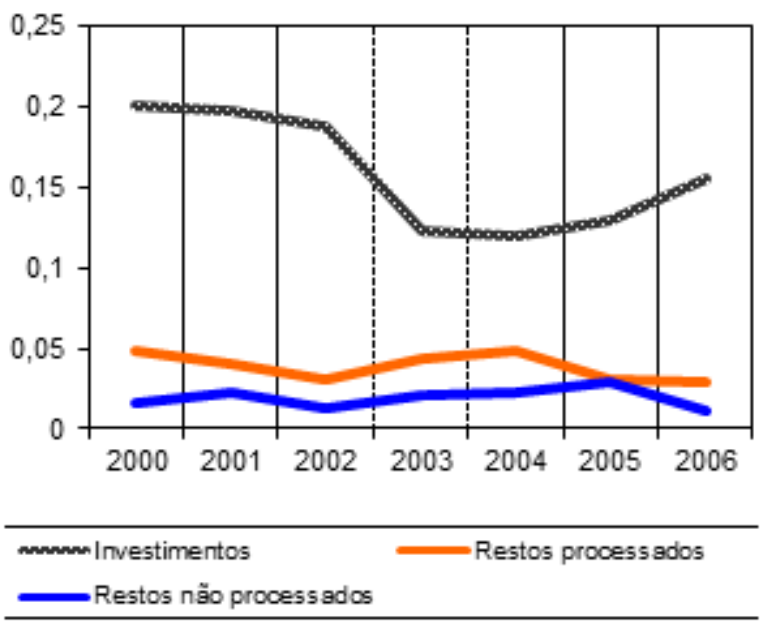

Estados com suficiência de caixa

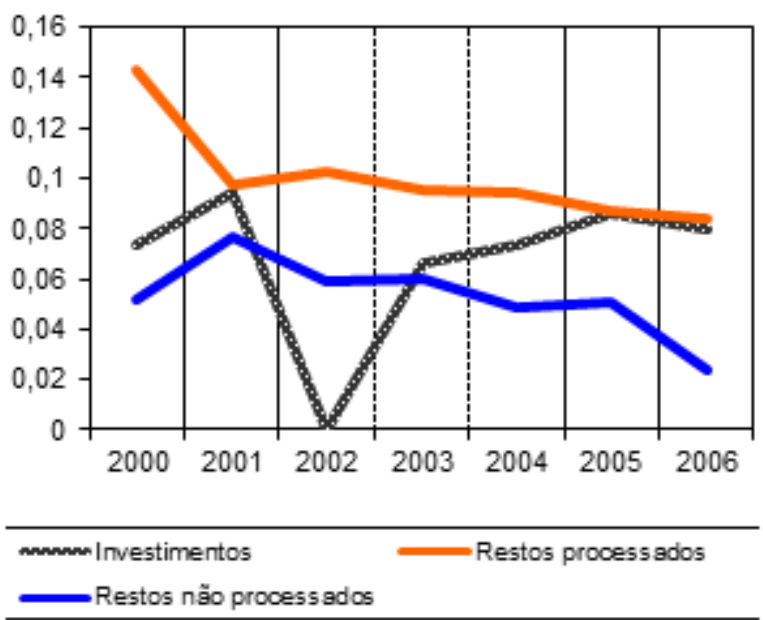

\footnotetext{
${ }^{2}$ A literatura pátria associa os investimentos de capital a fatores políticos. Por exemplo, ao investigar os gastos infraestruturais nos estados brasileiros pré-LRF, Teixeira (2001) verifica que, onde a competitividade política é superior, a proporção dessas despesas é mais el evada.
} 

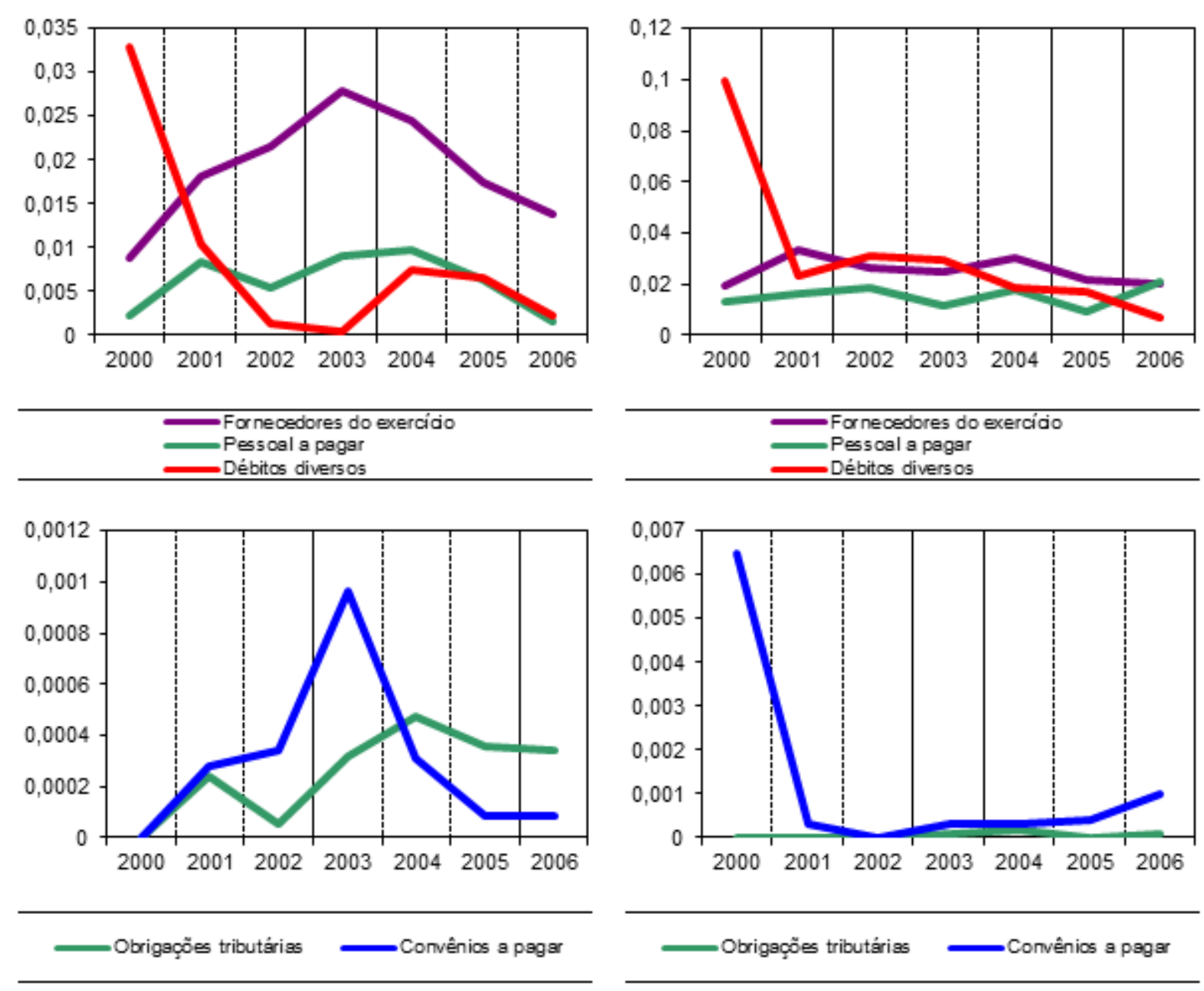

Fonte: STN, Souza (2008) e Melo et al. (2010).

À primeira vista os gráficos na Figura 4 obedecem a uma disposição errática, mas a razão entre o excedente de débitos em geral e a despesa corrente começa a cair a partir de 2001, justamente no ano em que os efeitos da reforma se percebem com mais intensidade no resultado primário, sendo o que se espera do padrão de austeridade iniciado com a LRF. Contudo, os restos das outras rubricas denotam ser isso uma exceção. A Figura mostra, por exemplo, que os excedentes de despesas com convênios são indicativos de diferentes decisões tomadas no decurso da execução orçamentária, visto que as curvas procedem de maneira oposta nos dois grupos. Isso significa que a sua postergação está relacionada à geração de déficits.

Percebe-se também uma variação expressiva nos restos relacionados a investimentos de infraestrutura (obras públicas), embora os dois grupos apresentem 
majorações no período pós-eleitoral, o que caracteriza certa ciclicalidade. Esses gastos apresentam aumentos motivados pelas promessas de campanha, com subsequente queda em finais de mandato por força das restrições legais, até retomarem trajetória ascendente à medida que os recursos vão sendo alocados conforme a nova agenda governamental. O mesmo se diz a respeito dos picos observados nos excedentes de despesas com fornecedores (os gráficos da linha do meio). Além disso, as curvas dos investimentos não guardam simetria com as dos restos, o que pode levar à suposição equivocada de que o oportunismo fiscal tem origem e se detém noutras despesas.

Há, entretanto, uma lógica para isso que, ainda que técnica, é também política: com o aguçamento da vigilância sobre o ano eleitoral, as majorações de despesa em investimentos ficam adstritas ao prazo ao quadrimestre inicial. Entretanto, as demandas por obras públicas não compreendem um jogo de uma rodada só. Os ritos de assédio mútuo entre os governantes estaduais, locais e grupos de interesse para a destinação desses recursos afluem no decorrer do mandato e se concretizam após as eleições como resquício da necessidade de se honrarem promessas de campanha e se assegurar a legitimidade dos mandatos.

A curva de restos com pessoal, conforme se vê nos gráficos da linha central da Figura, também sugere a antecipação do ciclo político no orçamento. A literatura sobre a economia do setor público da década de 90 identifica instâncias reiteradas de aumentos salariais na forma de patronagem política nos anos que precediam aos certames eleitorais. A LRF vem limitar este expediente, de forma que os acréscimos de restos a pagar nesta rubrica devem-se basicamente aos encargos sociais e previdenciários. Sob o jugo da LRF, isto vem a significar que o oportunismo retroage aos anos pré-eleitorais, principalmente nos estados deficitários. As despesas com pessoal inscritas nos restos são maiores e apresentam maior ciclicalidade nos estados com insuficiência de caixa.

A Figura 5 adiante mostra o comportamento dos restos a pagar de um grupo de estados identificados como detentores dos maiores déficits de caixa no período analisado. Na amostra incluímos deliberadamente e para fim exclusivo de comparação 
Figura 5 - Restos a pagar em uma amostra de estados

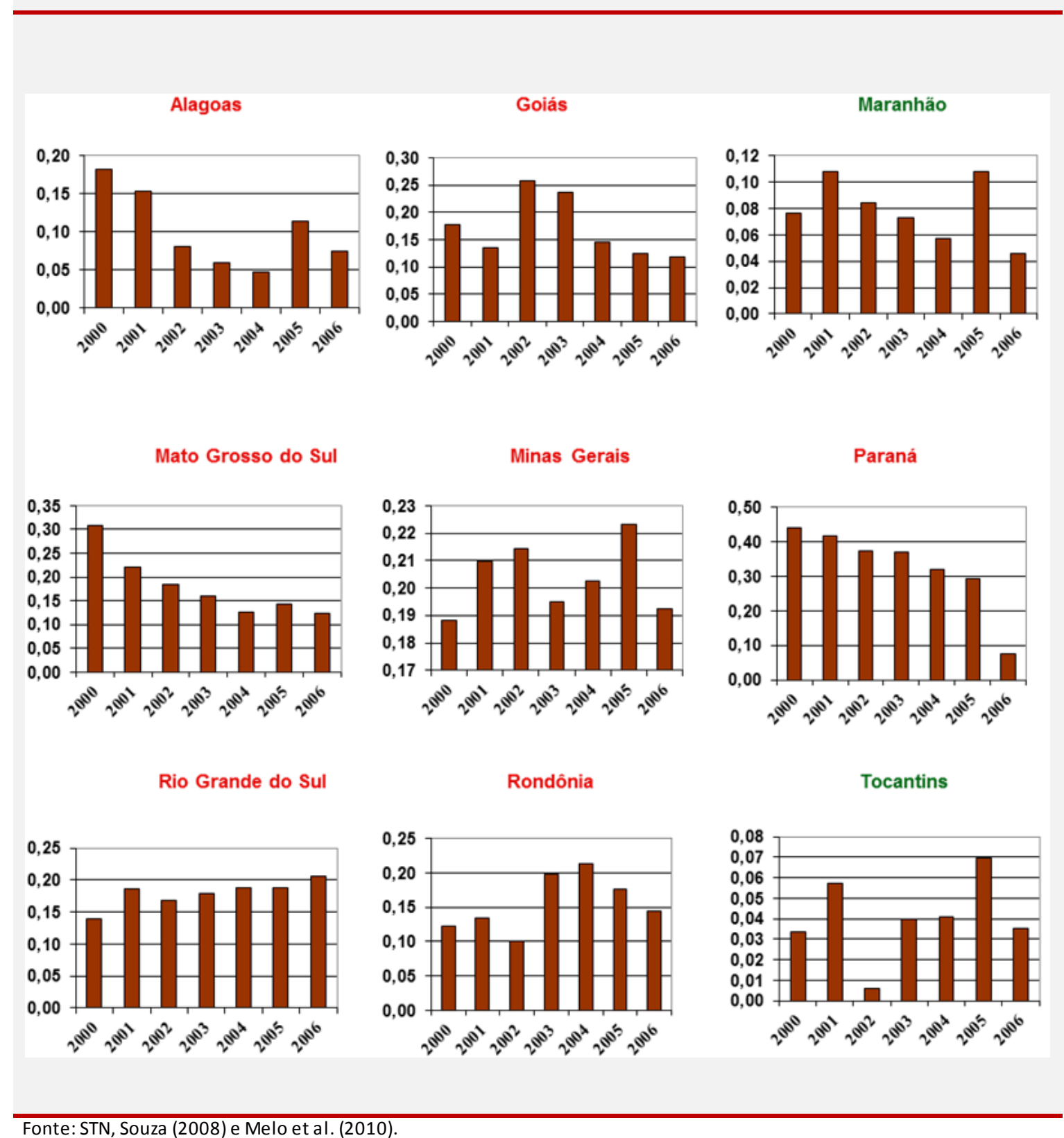

dois estados que apresentam a maior suficiência média de caixa. Observe-se que não há regularidade quanto a picos nos anos de eleição para o cargo de governador (2002 e 2006), o que torna notório que os impactos do oportunismo fiscal não reverberam unicamente em anos de certame. Tampouco a ciclicalidade nos excedentes de despesa parece mais evidente num grupo de estados do que no outro. O que todos apresentam em comum, isso sim, é o fato de fazerem uso dos restos como mecanismos de escape 
frente à austeridade das regras e à necessidade de mobilizarem recursos em função do que reputem como politicamente mais vantajoso.

Ao cabo, a análise gráfica delata ciclicalidade nos restos decorrentes de pagamentos a fornecedores, obras públicas, convênios e débitos em geral, inclusive em períodos pré e pós-sufrágio. Isso é indicação de que eventuais alocações oportunistas de despesas - ou o seu aumento sem disponibilidade imediata de caixa podem ser habilmente compensados com a postergação do pagamento de outros itens orçamentários. Mais ainda, o simples fato de a evolução dos restos a pagar apresentar comportamento irregular, em notório contraste com a estabilidade das curvas de resultado fiscal convencional após o ano 2000, é o que melhor ilustra a mudança do modus operandi associado ao comportamento fiscal oportunista.

Tendo isso por norte, os estados fazem uso variado do recurso, ora optando por uns itens de gasto, ora por outros, buscando ajustar suas preferências alocativas aos limites orçamentários exigidos pelas regras de austeridade em vigor, o que colateralmente pode conduzir a experiências de déficit e endividamento ou, alternativamente, à supressão de recursos em áreas politicamente menos atrativas. E, como se verá na seção seguinte, é esse o mecanismo que concede refúgio à mobilidade alocativa dos governos estaduais, na forma de uma endógena e relevante participação na composição dos gastos e destinação dos recursos que melhor se amoldem à agenda política dos indivíduos no poder.

\section{A noção de contabilidade criativa}

As regras de estabilização fiscal têm o condão de reprimir quedas bruscas de resultado fiscal politicamente induzidas. Ao atuarem sob restrições orçamentárias rígidas, os governantes buscam apresentar resultados fiscais condizentes com a inclinação nacional à austeridade. Contudo, o desempenho eleitoral dos governantes é a garantia de sua manutenção no poder. Como saída para esse dilema e, paradoxalmente, para a própria sustentação das regras, os estados recorrem a mecanismos de escape com o fito de manter sua mobilidade alocativa. 
Viu-se na seção anterior que os indicadores convencionais de desempenho fiscal não elucidam por que o tônus do oportunismo fiscal na vigência da LRF passa a depender da mobilidade de recursos no orçamento. Para tanto, é mister explorar indicadores que revelem o status real das contas estaduais e a dinâmica que leva a essa realidade. Argumentamos nesta subseção que, dadas certas circunstâncias, os governos subnacionais recorrem a mecanismos que assegurem a consecução de determinados objetivos fiscais, ou mediante formas legais de flexibilização dos limites e metas, ou através de manejos contábeis nas entrelinhas da execução orçamentária. Trata-se de uma forma de contabilidade criativa (creative accounting) a respeito do que a literatura tem dado diversos alertas (Kennedy e Robbins, 2001; Milesi-Ferretti, 2003; Bernoth e Wolff, 2006; Von Hagen e Wolff, 2006).

Segundo o estudo seminal de Milesi-Ferretti (2003), os ensaios teóricos ortodoxos partem da noção a priori de que as regras fiscais são plenamente efetivas no intento de induzir os governos deficitários a se engajar num comportamento fiscal virtuoso. Entretanto, o autor argumenta que na ausência de transparência orçamentária a probabilidade de emprego de contabilidade criativa é grande, por gerar uma impressão falsa de cumprimento das regras. O mais forte indício do uso do artifício, nos termos sugeridos pelo autor (2003: 379), é a melhora rápida e momentânea nos resultados fiscais de final de mandato que, por serem aparentes, não conseguem se sustentar de forma intertemporal. Veremos a seguir que, também no caso dos estados brasileiros, este é um sinal de que a contabilidade criativa torna-se uma das manifestações mais comuns de oportunismo fiscal na década de 2000.

Indícios de contabilidade criativa no Brasil são reportados pela literatura já no nível federal. Silva e Cândido Jr. (2007), por exemplo, ao exporem os pormenores dos registros de apuração do resultado primário da União, identificam situações reiteradas de postergação de despesas por meio dos restos a pagar. Dado que os restos não entram no cálculo do resultado primário, o governo mostra repetidos superávits nas viradas de ano. Outra particularidade dos restos é que são posteriormente inscritos na dívida consolidada, que também não se computa na apuração anual do resultado primário. Lima e Miranda (2006), por sua vez, advertem que os débitos com 
fornecedores registrados nessa modalidade funcionam como profícuos instrumentos de barganha política entre membros do Executivo e do Legislativo. Conquanto sua análise se restrinja às contas federais, os autores veem razões para que o subterfúgio contábil seja utilizado com ainda maior constância pelos governos subnacionais.

De fato, o uso generalizado de restos a pagar se replica nas evidências oferecidas na seção anterior, à medida que os estados assumem obrigações financeiras em volume superior a sua disponibilidade de caixa e preterem o pagamento dos excedentes. Ao recorrerem a esse mecanismo de escape, as metas de superávit são preservadas, visto que estas enfatizam o pagamento e não a realização da despesa, preservando-se, também, os resultados da estabilização fiscal nos estados. Por outro lado, a mobilidade alocativa subsiste ao rigor das regras e, com ela, a maior probabilidade de permanência nos cargos. Em última análise, a essência sutil desse mecanismo sugere que a austeridade não se sobrepõe ao oportunismo.

O recurso aos restos é legal, porém problemático do ponto de vista do equilíbrio intertemporal, dado que as obrigações assim contratadas têm lastro em receitas futuras e o potencial de adrede comprometerem os haveres do exercício seguinte, ou mesmo do governo subsequente. Todavia, dada a severidade das sanções, que podem ir da suspensão de repasses a processo criminal, o uso dos restos como forma de geração proposital de déficits para os sucessores no poder se condiciona a garantias de natureza política, granjeadas no âmbito das relações intergovernamentais ou, como veremos mais adiante, interpoderes.

A mobilidade alocativa pode, contudo, se valer de outros tipos de manejos contábeis, velados ou não, que facilitem o remanejamento de recursos dentro do orçamento. Por exemplo, ao se lançarem certas despesas na rubrica de outras se facilita a deferência aos limites arrolados nas regras para aquele item orçamentário. É o que ocorre quando não se inscrevem aposentadorias e pensões, IRRF ou verbas indenizatórias de servidores demitidos (precatórios) sob a linha de gastos com pessoal. Outro exemplo observado amiúde na fase inicial da estabilização fiscal: a inscrição de receitas de privatizações como receita corrente líquida, grandeza que baliza o ajuste das despesas e receitas às metas fiscais. Quanto maior a RCL mais vantajosa ela será, por verter em maior superávit primário. 
A abrangência e diversificação das operações oportunistas concorrem para a dificuldade de se atestar a veracidade dos registros contábeis ao final do exercício ou no ocaso do mandato. É razoável supor que nalgumas situações os melindres e a desorganização da contabilidade governamental contribuem para tal estado de coisas. Noutras, porém, a falta de transparência e a consequente manipulação oportunista dos recursos são a causa verídica de os números apresentados pelos estados não serem a expressão exata de suas cifras. Por este prisma, quaisquer análises que se balizem pelos dados oficiais da execução orçamentária escusam-se de não observar comportamentos promovidos com o fito de majorar resultados ou remanejar recursos à margem das restrições legais. Tal possibilidade só se ratifica mediante instrumentos de controle que possibilitem a interceptação imediata de ardis nas rubricas orçamentárias.

Caso contrário, o recurso à contabilidade criativa se torna deveras convidativo por possibilitar aos estados com insuficiência de caixa a prestação de contas nos padrões legais (os prazos, limites e metas são obedecidos de forma escritural), ou seja, sem o risco de terem as contas impugnadas pelos órgãos de controle. Outrossim, sendo as metas impostas sobre o resultado fiscal mensurável (no caso, o resultado primário), ao contrário da disponibilidade de caixa (não mensurável quando há assimetria de informações), as regras podem ser cumpridas de jure, mas não de facto. Ademais, conquanto o desempenho eleitoral guarde relação direta com a mobilidade de gastos e a austeridade fiscal, decorre que a contabilidade criativa se afigura como conveniente em ambas as aspirações.

Dada a ação simultânea de fatores que levam à disciplina fiscal e ao bom desempenho eleitoral, pode-se argumentar que o quadro de constrangimentos fiscais gera a tendência de se buscarem alternativas em prol do atendimento de demandas sociais, distributivas ou de infraestrutura. Nada obsta, porém, que a manipulação fiscal oportunista se preste a fins escusos. A contemplação do mundo fenomênico é elucidativa: gastos em profusão com propaganda eleitoral; aditivos reiterados a contratos de obras públicas; obras superfaturadas, notas fiscais "frias" ou fornecedores "fantasmas"; serviços públicos caros e de baixa qualidade; e a lista não 
se exaure. Os efeitos são também conhecidos do observador mediano: os governantes em início de mandato recorrem a cortes de despesas para a garantia da governabilidade, e.g., redução de cargos comissionados, cancelamento de licitações ou revisão de contratos, redução do número de secretarias e atrasos nos salários do funcionalismo ${ }^{3}$.

Portanto, com base na análise até aqui, é forçoso admitir que a falta de transparência nas informações fiscais é por vezes intencional, fomentando, qual manto, o uso de sutilezas contábeis. Nesse desiderato, de vários expedientes podem se valer os governantes para contornar o estorvo das regras no redirecionamento do gasto para onde melhor Ihes convier. Supondo o contrário, a probabilidade maior seria de suficiência de caixa ao final dos exercícios, mas a realidade financeira dos estados nos impele ao relaxamento da suposição para concluir, com fulcro no proposto $a$ priori, que 1) há ação oportunista sistemática nos orçamentos estaduais habilitada por meio da contabilidade criativa e 2) tal mecanismo de escape é subproduto bastardo da necessidade de alinhamento dos interesses estaduais às políticas macroeconômicas da União.

\section{Controles e lacunas: a importância das instituições}

Como se viu na subseção anterior, o oportunismo fiscal encontra terreno fértil em meio a problemas que variam de mera imprecisão contábil à proposital falta de transparência. Isso remete à efetividade das instituições de controle em identificar expedientes de contabilidade criativa nas contas estaduais e aplicar as sanções previstas nas regras. Com efeito, assegurar o fiel cumprimento das regras fiscais depende da independência política dos órgãos encarregados de fazer valer as suas sanções. A qualidade institucional dos tribunais de contas é, então, fator de interferência na habilidade dos governantes em se engajarem em comportamentos fiscais oportunistas. Esse aspecto é explorado em detalhe na presente subseção.

\footnotetext{
${ }^{3}$ Para uma gama de artifícios contábeis e seus efeitos numa amostra de estados brasileiros no período recente, ver Souza (2008).
} 
Com fundamento na literatura de economia política e nas evidências apresentadas nas seções anteriores, pode-se concluir que as oscilações nos excedentes de despesa dos estados, ostensivas ou encobertas, são, pelo menos parcialmente, atribuídas à gana maximizadora de votos dos atores políticos no poder. É inconteste, porém, que a falta de deferência plena às regras gera custos e constrange comportamentos. Se assim não fosse, o padrão pós-2000 de desempenho fiscal geral dificilmente seria positivo. No âmbito estadual, a operosidade dos tribunais de contas (TCEs) é emblemática neste sentido, face à constante inspeção do cumprimento de regras fiscais e utilização de recursos em políticas de interesse público.

Sem ir muito longe, é notório que o cumprimento, descumprimento ou cumprimento parcial das regras deriva da interpretação que Ihes dão os tribunais. À guisa de exemplo, o Artigo 42 da LRF traz a seguinte redação: “obrigação de despesa que não pode ser cumprida integralmente dentro do mandato ou que tenha parcelas a serem pagas no exercício seguinte sem que haja suficiente disponibilidade de caixa para este efeito." Interpretações latas a respeito do que venha a ser "disponibilidade de caixa" favorecem estratégias como a assunção de obrigações e sua eventual transferência para momentos futuros, ao passo que exegeses mais estritas podem suscitar o atraso proposital nas parcelas relativas ao refinanciamento da dívida pública ou postergação do pagamento de credores. Um curso de ação alternativo é o uso de lacunas legais oportuníssimas, como nos casos do reajuste da folha de pessoal em períodos anteriores à data limite (o quadrimestre inicial do último ano de governo).

Souza (2008) identifica interpretações variadas dos TCEs sobre que despesas devem ser registradas na rubrica de pessoal ou sobre o que seja Receita Corrente Líquida. Segundo o autor, os TCEs podem ver com diferentes olhos os arcanos dos demonstrativos financeiros, particularmente aqueles conducentes a resultados primários mais elevados, como a exclusão do Imposto de Renda Retido na Fonte, da contribuição dos servidores para os Fundos de Saúde, das receitas vinculadas (transferências do SUS, do Salário Educação/FNDE, etc.), da inclusão de perdas com o FUNDEB, ou da anulação dos restos a pagar (quando o ente registra a anulação como receita do exercício, a $\mathrm{RCL}$ resulta maior). É possível, portanto, que interpretações 
desiguais se reproduzam desigualmente nos resultados fiscais; e isto não é um problema marginal.

É imperioso ratificar que os registros que embasam as auditorias dos tribunais são elaborados pelos próprios entes federados, os quais, na linha do nosso argumento, submetem-se ao confronto entre austeridade e oportunismo. Por uma parte, isto conduz à baixa confiabilidade das informações; por outra, à falsa - muito embora politicamente conveniente - impressão de que as regras são cumpridas de forma cabal. Se assim não fosse, não haveria informações contraditórias dos governantes que entram e dos que saem acerca de saldos em caixa, tampouco precariedades na divulgação de atos discricionários de gestão fiscal, como a concessão de incentivos a segmentos empresariais. A falta de transparência fornece, portanto, os passos para a consolidação da contabilidade criativa como método hodierno de oportunismo fiscal.

Como corolário, a extensão e frequência de uso da contabilidade criativa estão vinculadas à habilidade das instituições de controle externo em identificar e punir esse comportamento. Ao invés, a ausência de punições por sucessivos atos de oportunismo produz incentivos para a consolidação da práxis. Em outras palavras, os governantes mantêm-se disciplinados até o limite de seus interesses corporativos. A partir daí a disciplina fiscal só é alcançada pela via punitiva. Um problema correlato é o grau de autonomia ou independência política dos tribunais, já que o contingente de conselheiros de contas é majoritariamente composto de ex-políticos ou pessoas que aquinhoam laços familiares ou partidários com políticos em atividade ${ }^{4}$. Muitos dos postos são ocupados por predileções das assembleias legislativas e governadores, o que torna o colegiado alvo de incursões políticas. Diante disso, é de se esperar que os liames políticos entre conselheiros de contas e governadores funcionem como incentivo ao desdém às regras, devido à possibilidade de troca de favores entre uns e outros.

No longo termo isso mina a efetividade das instituições de controle em criar resistência ao oportunismo fiscal, ao passo que as tentativas reformistas para incutir

\footnotetext{
4 Souza (2008: 179) sustenta que "perto de 90\% dos integrantes dos colegiados das 27 unidades federativas têm em seu currículo o cargo de deputa do estadual ou federal, secretário de estado, prefeito e vereador, ou são consanguíneos de políticos, gente de sua confidência, enquanto os servidores de carreira se espremem no percentual restante".
} 
independência política nas cortes têm produzido menos sucesso que malogro: os governadores empenham sua influência na arena parlamentar em favor do status quo. Isto porque, com a adoção de mecanismos de controle efetivos e independentes, os rigores das regras tornam-se empecilhos para que os líderes políticos levem adiante seus propósitos oportunistas, no sentido aqui discutido, ainda mais quando os mecanismos de controle inibem os mecanismos de escape. $O$ apego ao antigo estado de coisas é, por este prisma, uma ameaça aos ganhos da reforma de estabilização fiscal, uma vez que a insistência em contrariar regras no fragor dos embates políticos pode não apenas gerar turbulência fiscal para administrações futuras, mas também ameaçar coletivamente o equilíbrio das contas subnacionais.

Não se pode afirmar, ainda assim, que a atuação e autonomia dessas instituições sejam absolutamente homogêneas entre as unidades federativas; e esses diferentes graus de enforcement geram estímulos variados ao uso de contabilidade criativa. Em função disso, Melo et al. (2009) crêem ser possível alcançar autonomia no julgamento das contas a despeito do misto de interesses políticos nos TCEs, desde que o nível de competição eleitoral entre as elites seja tal que garanta uma representação variada de grupos políticos nas recâmaras das instituições. A nomeação de conselheiros por elites rivais que se alternam no poder levam a este equilíbrio de forças. Alcançado o equilíbrio, as regras concebidas como pilares da disciplina fiscal têm mais chances de se sustentarem ao longo do tempo visto que as instituições encarregadas de garantir seu cumprimento não são capturadas por interesses políticos de quem se espera cumpri-las. Caso contrário, as regras se tornam decrépitas antes de eficazes.

Por toda a centralidade que têm as instituições de controle externo na intimativa de que os alicerces da disciplina fiscal permanecerão sólidos ante a volubilidade dos interesses que rodeiam o orçamento público, sua fragilidade institucional é incentivo ao oportunismo para os governantes que se beneficiam de julgados lenientes, ou quando recomendações para a aplicação de penalidades são debalde encaminhadas pelos tribunais às assembleias legislativas, onde a influência do governador é decisiva. É assim que a tolerância expressa ou tácita aos deslizes fiscais 
fornece incentivos ao oportunismo: os governantes maximizam a sua utilidade ao se beneficiarem de irregularidades que, sabem, serão posteriormente absolvidas pelas cortes, ou por seus pares. Os incentivos para a rotina são óbvios: colhem-se os benefícios dos expedientes no curtíssimo prazo e lançam-se os custos para momentos futuros ou incertos. Devido à arquitetura das relações interpoderes e intergovernamentais historicamente firmadas, a ruptura de tal estrutura de incentivos não passa de uma quimera.

Em síntese, a austeridade fiscal deve-se entender como associada à independência política das instituições de controle externo. Na prática, porém, as barreiras ao comportamento oportunista ruem com a ausência de enforcement das sanções previstas nas regras, das quais muitas vezes se escapa pela via sutil da contabilidade criativa. Outras vezes capitulam as sanções ante as decisões políticas tomadas na ciranda das interações entre executivo e legislativo, ou das relações dos estados com o governo federal. Como se verá na próxima subseção, este aspecto se insere na complexidade de fatores que explicam a persistência do oportunismo em plena era da austeridade, ainda que com variações quanto à forma, magnitude e periodicidade.

\section{Breve exercício empírico}

A presente subseção se dedica a testar empiricamente a hipótese que norteia 0 trabalho, qual seja, se há associação entre variáveis políticas e institucionais e o oportunismo fiscal dos governantes. Mais precisamente, discute-se até que ponto o uso de contabilidade criativa se correlaciona com as variáveis selecionadas. A escolha das variáveis baseia-se na literatura teórica, nos dados disponíveis após a reforma de estabilização fiscal e nos seus potenciais efeitos sobre o comportamento fiscal dos estados. Eventuais aspectos sociais e econômicos não são submetidos a teste, visto fugirem do alcance do modelo conceitual empregado. O mesmo tratamento é dado a fatores de ordem histórica. 
O período selecionado (2000-06) constitui uma amostra não-randômica, porém perfeitamente representativa do comportamento fiscal oportunista no transcorrer da década de 2000. Isto implica que não se pode, nos anos subsequentes, abandonar a hipótese de ocorrência de contabilidade criativa. Embora a estatística empregada seja relativamente simples, é de se esperar que suas inferências sejam razoáveis, visto que não se pretende aqui estabelecer uma relação exata de causalidade entre as combinações de variáveis e determinado indicador de resultado fiscal. O empreendimento é menos ambicioso: enxergar alterações no comportamento do indicador de contabilidade criativa na presença das variáveis selecionadas.

Viu-se que há grande variação nos restos de estado para estado durante o setênio analisado. O que explica tal variação? Voltemos atenção analítica para este indicador na presente investigação quantitativa, tomando-o por proxy da contabilidade criativa. Embora os restos não se constituam no único nem, talvez, no mais apropriado parâmetro de mensuração da contabilidade criativa, visto que, por definição, estão igualmente sujeitos ao expediente, são eles, conforme previamente demonstrado, que melhor se relacionam com a insuficiência de caixa, findos os exercícios financeiros.

Uma intrigante indagação é saber se a paga prevista para os governos que se distanciam dos padrões de austeridade fiscal ou, no caso aqui discutido, geram excedentes propositais de despesa, é percebida como suficiente para inibir o comportamento oportunista. Associações estatísticas entre determinados atributos das instituições de controle externo e os restos a pagar podem elucidar esta questão.

Está implícito na argumentação da subseção anterior que a qualidade institucional dos tribunais de contas relaciona-se ao uso de contabilidade criativa. Um dos aspectos dessa qualidade é o grau de ativismo do TCE. Segundo Melo et al. (2009), tribunais ativos são aqueles que executam mais do que o mínimo necessário nas auditorias das contas. $\mathrm{O}$ ativismo é medido, por esse critério, em termos da razão entre o número de relatórios de auditoria realizados por cada tribunal e o número de unidades administrativas sob sua juris dição.

Um outro parâmetro de qualidade institucional é o grau de independência política dos tribunais. Novamente recorrendo à literatura, Melo et al. sugerem que 
uma das principais variáveis explicativas dessa independência é a presença ou ausência de auditores de carreira ou promotor público no pleno do tribunal, e não apenas conselheiros indicados por critérios preponderantemente políticos. Uma vez que colegiados com tal composição estão mais propensos à ação politicamente independente, incluímos no modelo uma variável dummy com valor 1 se o TCE dispõe de auditor de carreira no colegiado ou 0 se não dispõe. Em outras palavras, espera-se que a presença dos auditores nas instâncias superiores da corte restrinja a ocorrência de contabilidade criativa.

Com o objetivo de se lidar com os efeitos das eleições na probabilidade de os estados incorrerem em insuficiência de caixa, incluem-se nos modelos variáveis de alternância de governo e fragmentação partidária das assembléias legislativas. A primeira equivale à expectativa de reeleição $0^{5}$. Tendo por fundamento a literatura antes mencionada, espera-se um coeficiente positivo entre a mudança de governador e a insuficiência de caixa. Ou seja, quanto maior o risco eleitoral, maiores serão os incentivos para transferência de déficits a sucessores rivais. A fragmentação partidária, por sua vez, tem a ver com o número de partidos políticos por assento. Assume-se que, quanto maior a fragmentação, mais dificuldades tem o governador para coordenar sua coalizão na assembléia, o que gera maior necessidade de dispêndio e, por conseqüência, maiores incentivos para o recurso à contabilidade criativa.

Controla-se pelo PIB estadual per capita na suposição de que estados mais ricos tendem a apresentar pior situação fiscal por razões diversas, inclusive pela maior habilidade de contrair dívidas e por depender menos das transferências federais, ao contrário dos mais pobres. Da dependência dos repasses redunda que o custo da indisciplina encontra seu ápice na sua retenção (Art. 11 da LRF), quando os repasses da União aos estados ficam por penhor da produção de superávits primários.

Os resultados dos testes se encontram na Tabela 1:

\footnotetext{
5 Construído com base nas três ultimas eleições para governador (1998-2006), o índice varia de 0 (quando a mesma coalizão vence nos três episódios eleitorais consecutivos) a 4 (quando nenhuma das coalizões consegue vencer duas el eições seguidas).
} 
Tabela 1: Determinantes da contabilidade criativa dos estados 2000-2006

\begin{tabular}{|c|c|c|c|c|c|}
\hline Modelos & (1) & (2) & (3) & (4) & (5) \\
\hline \multirow{2}{*}{ Ativis mo do TCE } & $-0,031 * *$ & $-0,026 * * *$ & $-0,023 * *$ & $-0,020 * *$ & $-0,023 * *$ \\
\hline & $(0,013)$ & $(0,014)$ & $(0,011)$ & $(0,010)$ & $(0,012)$ \\
\hline Alternância de & & $0,057 * * *$ & $0,070 * * *$ & $0,057 * * *$ & $0,054 * * *$ \\
\hline governo & & $(0,017)$ & $(0,014)$ & $(0,015)$ & $(0,017)$ \\
\hline $\begin{array}{l}\text { Auditores no } \\
\text { colegiado }\end{array}$ & & & $\begin{array}{l}-0,082^{* *} \\
(0,044)\end{array}$ & $-0,067 *(0,038)$ & $\begin{array}{l}-0,062^{*} \\
(0,038)\end{array}$ \\
\hline $\begin{array}{l}\text { Fragmentação } \\
\text { partidária }\end{array}$ & & & & $1,236 *(0,736)$ & $\begin{array}{l}1,121^{*} \\
(0,745)\end{array}$ \\
\hline PIB percapita & & & & & $\begin{array}{l}5,87 e-06 \\
(0,00001)\end{array}$ \\
\hline Constante & $0,013^{* * *}$ & $0,121 * * *$ & $0,143^{* *}$ & $-0,970$ & $-0,884$ \\
\hline Constante & $(0,039)$ & $(0,046)$ & $(0,051)$ & $(0,646)$ & $(0,654)$ \\
\hline$N$ & 189 & 189 & 189 & 189 & 189 \\
\hline $\mathrm{R}^{2}$ & 0.09 & 0.32 & 0.40 & 0.48 & 0.49 \\
\hline
\end{tabular}

Demonstra-se que a magnitude dos restos a pagar se correlaciona positivamente com o número de partidos políticos na assembléia. O resultado se alinha com a corrente da literatura que enfatiza o oportunismo dos governantes ao destinarem recursos para atender as preferências dos partidos pertencentes à coalizão, ou para beneficiar projetos de outros partidos em troca de apoio à reeleição, ou para outras facilidades decursivas do conchavo. Portanto, tudo o mais constante, há evidências de que assembléias estaduais altamente fragmentadas estão associadas a maior probabilidade de uso de contabilidade criativa pelo Executivo do que as menos fragmentadas.

Outra pressuposição teórica é que a expectativa de reeleição - ou a alternância de governo - funciona como incentivo para se aumentar o gasto e registrar o aumento nos restos a pagar. A variável mostra-se altamente significativa e positivamente correlacionada com a magnitude do indicador. Ou seja, a grande expectativa de mudança de governo pode resultar em maiores despesas, ou maior necessidade de registrar despesas em outras rubricas, levando ao uso de expedientes fiscais oportunistas. A predição, portanto, é que, na presença de incerteza eleitoral, há maiores incentivos para o recurso à contabilidade criativa.

O ativismo dos tribunais de contas e sua independência política são também fatores importantes na decisão dos governantes de gerar déficits de caixa, já que o 
sinal negativo de ambas as variáveis indica que TCEs ativos e autônomos tendem a refrear o emprego de expedientes fiscais oportunistas. Inversamente, quanto maior a influência política nos tribunais, maiores incentivos terão os governadores para recorrerem a mecanismos escusos. O oportunismo fiscal, portanto, não se explica exclusivamente pelos incentivos políticos com que os governantes se deparam, mas também pela forma como eles percebem e antecipam os custos incidentes, dada a probabilidade de incorrerem nas sanções que acompanham a infringência às regras. Assim, a vigilância sobre as contas públicas comina em custos para o uso da contabilidade criativa.

Com base nesses resultados, chegamos a duas principais conclusões: 1) Há evidência de oportunismo fiscal nos estados uma vez que as variáveis políticas se correlacionam positivamente com a insuficiência de caixa. Dada a presença de regras de austeridade fiscal, tal oportunismo se viabiliza por meio da contabilidade criativa. 2) $\mathrm{Na}$ medida em que os tribunais não sejam imunes à influência de deputados e governadores, há evidência de que a baixa autonomia desses TCEs esteja associada ao uso mais constante de contabilidade criativa.

A hipótese principal do trabalho resta, afinal, comprovada. A ocorrência constante de insuficiência de caixa em grande parte dos estados brasileiros no setênio analisado é resultante de o compêndio de reprimendas das regras fiscais e seus mecanismos institucionais de enforcement não granjearem aplacar o ímpeto oportunista dos atores políticos no poder, o que concede solidez à tese de soturna contabilidade criativa. Isto por fim favorece o revés implícito ao longo do trabalho: quando a probabilidade de se detectarem mecanismos de escape é baixa e os benefícios eleitorais do oportunismo fiscal são altos, os governantes não subordinam suas preferências alocativas à austeridade das regras e ao rigor das instituições.

Tais inferências implicam que o desempenho fiscal é produto não somente da austeridade das regras fiscais, mas também dos tradicionais incentivos políticos ao aumento sazonal dos gastos públicos; incentivos que não são eliminados pelas sanções previstas nas regras, ou pelo potencial punitivo das cortes de contas, as quais se mostram insuficientes para pôr fim à ação oportunista dos governadores no decorrer da década. Os efeitos desse oportunismo, embora não se observem no aumento 
exponencial de gastos, aparecem na mudança de sua composição e na inscrição de despesas em restos a pagar, o que explica não haver necessariamente geração de déficits nominais ou primários. Em outras palavras, ainda que não se perceba na curva agregada do resultado fiscal um movimento ondulatório bem definido com baixas repentinas a intervalos regulares, um movimento menos perceptível ocorre nas entranhas das contas públicas e se acelera no ardor dos turnos e returnos eleitorais. Ao fim e ao cabo, o oportunismo fiscal dos estados brasileiros tem agora por estrado a contabilidade criativa.

\section{Referências bibliográficas}

Alston, L., Melo, M., Mueller, B. e Pereira, C. 2005. "Who Decides on Public Expenditures? A Political Economy Analysis of the Budget Process: The Case of Brazil." IADB Economic and Social Study Series, RE1-05-006.

Bernoth, K. e Wolff, G. 2006. "Fool the markets? Creative Accounting, Fiscal Transparency and Sovereign Risk Premia." DNB Working Paper No. 103.

Botelho, R. 2002. "Determinantes do Ajuste Fiscal dos Estados Brasileiros." VII Prêmio Tesouro Nacional. ESAF. Brasília.

Cossio, F. A. 2001. "O Comportamento Fiscal dos Estados Brasileiros e seus Determinantes Políticos." ANPEC. Economia, 2(1): 209-258.

Giambiagi, F. 2007. „Dezessete Anos de Política Fiscal no Brasil: 1991-2007.“ IPEA. Texto para discussão no 1309 .

Gobetti, S. e Klering, L. 2007. "Índice de Responsabilidade Fiscal e Qualidade de Gestão: Uma Análise Combinada Baseada em Indicadores de Estados e Municípios." XII Prêmio Tesouro Nacional. ESAF. Brasília.

Kennedy, S. e Robbins, J. 2001. "The Role of Fiscal rules in Determining Fiscal Performance." Canada Department of Finance Working Paper no 2001/16.

Kopits, G. 2004. Rules-Based Fiscal Policy in Emerging Markets: Background, Analysis and Prospects. Palgrave Macmillan.

Lima, E. e Miranda, R. 2006. "Processo Orçamentário Federal Brasileiro." In: Marcos Mendes. (Org.). Gasto Público Eficiente: 91 Propostas Para O Desenvolvimento do Brasil. Rio de Janeiro: Topbooks.

Melo, M., Pereira, C. e Figueiredo, C. 2009. "Political and Institutional Checks on Corruption: Explaining the Performance of Brazilian Audit Institutions." Comparative Political Studies, 42 (9): 1217-1244. 
Melo, M., Pereira, C. e Souza, S. 2010. "The Political Economy of Fiscal Reform in Brazil: The Rationale for the Suboptimal Equilibrium". IADB Working Paper no 117.

Milesi-Ferretti, G. M. 2003. "Good, Bad or Ugly? On the Effects of Fiscal Rules with Creative Accounting." Journal of Public Economics, 88: 377-394.

Poterba, J. 1994. "State Responses to fiscal Crises: The Effects of Budgetary Institutions and Politics." Journal of Political Economy, 102: 798-821.

Rogoff, K. 1990. "Equilibrium Political Budget Cycles." American Economic Review, 80: 21-36.

Roubini, N. e Sachs, J. 1988. "Political and Economic Determinants of Budget Deficits in the Industrial Democracies." NBER Working Paper no W2682.

Sátyro, N. G. 2006. "Política nos Estados Brasileiros e Gastos Sociais: uma Análise de Série Temporal com Corte Transversal - 1987 a 2002." In: Souza, C. e Neto, P. F. (2006). Governo, Políticas Públicas e Elites Políticas nos Estados Brasileiros. Rio de Janeiro. Revan. pp. 57-90.

Silva, A. e Candido Jr., J. 2007. "Uma Análise da Consistência do Superávit Primário no Brasil." Boletim de Desenvolvimento Fiscal, no 4. IPEA.

Souza, S. S. 2008. A Fria Austeridade das Regras Fiscais Resiste ao Calor das Urnas? Oportunismo Fiscale Contabilidade Criativa nos Estados Brasileiros. Tese de Doutorado. UFPE.

Teixeira, M. F. 2001. "Composição dos Gastos dos Estados Brasileiros, 1983/99." VII Prêmio Tesouro Nacional. ESAF. Brasília.

Von Hagen, J., e Wolff, G. 2006. "What Do Deficits Tell Us About Debt? Empirical Evidence on Creative Accounting with Fiscal Rules in the EU." GESY. Discussion Paper No. 148. 